\title{
Corpus-Assisted Comparative Study of British Job Advertisements: Sociocultural Perspective
}

\author{
L. A. Kochetova \\ English Philology Chair \\ Volgograd State University \\ Volgograd, Russia \\ kochetova@volsu.ru \\ N. Yu. Sorokoletova \\ English Philology Chair \\ Volgograd State University \\ Volgograd, Russia \\ sorokoletovanat@ volsu.ru,
}

\author{
E. Yu. Ilyinova \\ English Philology Chair \\ Volgograd State University \\ Volgograd, Russia \\ , ilynov@volsu.ru \\ O. S. Volkova \\ English Philology Chair \\ Volgograd State University \\ Volgograd, Russia \\ olgavolkova@volsu.ru
}

\begin{abstract}
The paper provides a nuanced picture of discursive practices used in the professional genre of job advertisements through a comparative study of key words retrieved from adverts for leading and non-leading positions. The corpus compiled includes texts available on websites of the two national British newspapers The Times and The Guardian. The methodology of corpus linguistics is applied with the purpose to explore the semantic difference in the key word data that are used to describe requirements for leading and non-leading job categories, in this way revealing similarities and differences in the patterns of meaning that are determined by socio-cultural peculiarities of the genre. The semantic analysis shows that texts for leading positions are characterized by prevalence of lexis with meaning of power, change and planning used in the job description. Advertisements for non-leading positions comprise lexis that belong to the semantic categories of help, organization and reciprocity that focus on everyday activities. The two corpora also reveal significant differences in the way qualities and attributes of an ideal candidate are discursively construed in the two job categories. Applying the framework of Appraisal Theory, the study reveals that evaluative lexis is not evenly distributed in the two corpora. While key words specifying requirements for an ideal candidate, related to the subcategory of Capacity, are common for the two corpora, evaluative lexis related to the subcategories of Tenacity and Propriety is mainly found in the corpus of texts for non-leading jobs.
\end{abstract}

Keywords-genre; job advertisement; corpus; corpus linguistics

\section{INTRODUCTION}

This study is conducted within the framework of Discourse Analysis [1-4] and Appraisal Theory [5], as it provides data from a corpus-assisted investigation of the English-language job advertisements published by companies on the websites of the two national British newspapers, The Times (https://www.thetimes.co.uk/) and The Guardian (https://www.theguardian.com/). Being characterised by a range of formal conventions $[6,7]$, job advertisements are set in a particular social context and used by a specific discourse community to reach a set of established communicative goals [8]. The genre situatedness, that is the focus of the Genre Theory, is observed as it repeatedly occurs when there is a need to recruit suitable employees who meet the requirements specified by companies or organisations. As companies compete over not only resources and market shares but also over 'human capital', job advertisements become "the key strategic opportunity for enhancing competitive advantage" [9]. As this overall communicative goal of organisations is culturally and socially sensitive to the context in which a company operates in order to get a favourable response, they employ lexis that represents the company's position on the market and gives strong clues to how job applicants must write their resumes and present themselves at job interviews [10].

Research papers, devoted to investigation of this type of discursive practice, analyse language features of the genre that is set in various cultural contexts [11, 12], describe communicative moves employed and short-term diachronic changes in the genre schemata, register and content [13-8], study the genre in cross-cultural perspective [19-24]. However, the studies mentioned above do not reveal differences in discursive practices that are used by companies and organisations to promote senior and junior positions that often display variation in the lexis employed and values that underpin language structures.

Recently, the thrive of corpus linguistics has led to incorporation of corpus methodology into discourse and genres studies that use corpora as a source of material of real language uses [25-33]. First used for the purpose of quantitative analysis of lexis and syntax, corpus methodology has started to be applied for discourse analysis that aims at interpretation of language structures used in discursive practices within sociocultural context, in which genres are representatives as they reflect complex relationship between 
language and society. Even though job advertisements have been researched in various perspectives, they have not been subject to the study within the framework of the corpus-based approach. The paper addresses this gap by investigating how leading and non-leading positions in the job advertisements are discursively constructed by exploring key words that convey not only culturally but also socially specific values that are used to recruit suitable employees. The authors' hypothesis is that there are observable differences in lexical choices between the two corpora in the ways jobs are discursively constructed, and that they are determined by the type of vacancy offered. Given that leading and non-leading vacancies require not only different levels of qualification, experience, and education but also specific abilities, attributes and personal qualities, the authors assume that there is a difference in the evaluative meanings between the two subcorpora that can be captured in terms of Appraisal Theory.

As previous research shows, evaluation, which is central to Appraisal that deals with the construing of "shared feelings and values" [5, 34], is a characteristic feature of the genre under investigation [12]. As job advertisements possess evaluative meanings, the analysis focuses on one of the three domains of Appraisal, namely Judgment, which concerns with assessments of behavior. The category of Attitude, that is further divided into Affect, accounts for expressions of feelings; and the category of Appreciation, which comprises evaluations of things and natural phenomena [5], is not common in the texts under investigation. Judgement, that is the central category in the present study, is oriented towards either 'social esteem' or 'social sanction' [5]. The social esteem is associated with the three subcategories: Normality, Capacity and Tenacity. 'Normality' is related to how unusual someone is; 'Capacity' is oriented to how capable they are; and 'Tenacity' answers the question of how resolute they are. The behavior that evokes social sanctions is represented by the categories of Veracity (truth) and Propriety. Judgements of sanction have to do with 'veracity' (how truthful someone is) and 'propriety' (how ethical someone is). The category of Appreciation, that is seen as institutionalised feelings, is less common in this genre, but its incidences are observed in the corpus and are presented by the category Valuation, which answers the question (how innovative, authentic, timely, etc. someone is).

The study will try to answer the following research questions: (i) do the key words in the two sub-corpora differ in terms of semantic categories used to discursively construe the job description and the type of skills and personal characteristics required for different job categories? (ii) What type of key lexical items do companies use to describe qualities and attributes of an ideal candidate for leading and non-leading positions? (iii) What do the key lexical items disclose about the possible salient patterns of meaning? What evaluative categories do they belong to?

To achieve this objective, the study employs methods of corpus linguistics to identify the key words that are specific for the two corpora and examine similarities and differences between the range of keywords in the two corpora of job advertisements written in English and published by companies on the websites of the two British national newspapers The Times and The Guardian.

Some of the data, obtained from the corpus analysis of the texts, receive an in-depth contextual analysis of keywords to highlight patterns of meaning the job advertisements use to achieve their communicative goal. Besides, the variations found in the list of keywords, employed for job descriptions, keywords that are related to attributes, abilities and qualities of a suitable candidate will be reported. This type of approach will help to shed light on the value foci chosen by companies in promotion of senior and junior jobs to attract ideal candidates and achieve the purpose of communication.

\section{Methodology AND MATERIAL}

\section{A. Research design}

Having the goal to compare discursive practices used in the professional genre of job advertisement, the research was designed to investigate semantic categories, expressed by key words in the two corpora, and to reveal specific values, used by companies to promote jobs for leading and non-leading positions. Firstly, by using the corpus linguistics method, the keywords in the two corpora were identified, i.e. the unusually frequent lexical items defined against a reference corpus, which can enable the detection of recurrent patterns of meaning that would otherwise be difficult to access and recognize, especially in a horizontal reading of texts in a corpus [35, 36]. These were identified by AntConc software tool [37] that builds and then compares the frequency lists of the two corpora: a reference corpus and a corpus which keywords one is interested to find out. The choice of the reference corpus has a direct impact on the results obtained as different lexical items can be identified as key in the corpus under investigation. That is why the selection of the reference corpus is very important. As the purpose of the study is to conduct a comparative analysis of the two corpora, it is appropriate to use each of the corpora as a reference one. Therefore, lists of the keywords for the two corpora were compiled and compared against each other. Lexical items related to ideal candidate's requirements and job descriptions were selected manually and put into a table with indicated Keyness Score $(K)$. At the next stage, the key lexical items from the two corpora were categorized along the following categories: semantic categories and evaluation categories,

The amount of data obtained from the corpus was used for an in-depth contextual analysis of the keywords with the aim to identify the lexis used to construe values used by companies for job promotion. Given that there are the general shifts in economic structures and a growing share of services in employment [38], it is crucial to understand what types of skills are required in the job categories under investigation, whether, indeed, there is a large discrepancy in the requirements between leading and non-leading occupations, and how this difference can be conceptualised. Due to the rather ambiguous and subjective nature of skills perception, different sectors and occupations might reveal nuances and peculiarities in the depiction of jobs placing focus on different skills and requirements for an ideal candidate. 
To answer the first research question, the keywords from each of the lists were categorized along the job description as they are represented in the texts, and their semantics was revealed. To answer the second research question, lexis that represents requirements for an ideal candidate was manually selected. Finally, the lexis chosen was categorised along the evaluative categories, and the analysis of the implied meanings was conducted to reveal differences in the evaluative categories the keywords are associated with. As keywords are likely to point to patterns of meaning, especially if their collocations are regarded, collocations for some of the node words were explored to identify patterns of meaning they convey.

\section{B. Corpus design}

The corpus consists of the two sub-corpora that include texts retrieved from the sites of the two British national newspapers The Times and The Guardian. The texts were extracted from the categories 'Executives' and 'Secretarial' published on the websites between April 2016 and April 2017 that are treated as senior and junior positions in the company. The corpus for prestigious positions includes job advertisements under the headings 'Executives' with salaries of around $100 \mathrm{~K}$ whereas the corpus for junior positions is comprised of texts under the heading 'Secretarial' that offer jobs with salaries of less or around $40 \mathrm{~K}$. The size of each corpus is approximately 50, 000 words. The composition of the corpus under investigation is presented in Table I.

TABLE I.

THE STRUCTURE AND SIZE OF THE CORPUS

\begin{tabular}{|c|c|c|c|}
\hline Corpus & $\begin{array}{c}\text { Number of Tokens for } \\
\text { Corpus }\end{array}$ & $\begin{array}{c}\text { Number of } \\
\text { Texts }\end{array}$ & $\begin{array}{c}\text { Average } \\
\text { Number } \\
\text { of Tokens } \\
\text { per Text }\end{array}$ \\
\hline $\begin{array}{c}\text { Leading } \\
\text { positions } \\
\text { (CLP) }\end{array}$ & 51,140 & 137 & 373 \\
\hline $\begin{array}{c}\text { Non- } \\
\text { leading } \\
\text { positions } \\
\text { (CNPL) }\end{array}$ & 54,944 & 185 & 296 \\
\hline
\end{tabular}

\section{RESULTS AND DISCUSSION}

Varying numbers of key words were discovered in the two corpora: 81 keywords - in the corpus for non-leading positions (CNLP), and 57 keywords - in the corpus for leading positions (CLP). The two lists of keywords are distinct from each other as the authors used each of the corpora as a reference corpus to identify them. As the purpose of the study is to portray the difference in the description of the position and requirements, the lexis related to the location of the employer, etc. is not included in Table II. A threshold point at a minimum keyness 7.00 was set, and the lexical items, which have lower keyness than that indicated above, were excluded from the key word list. Further, both lists were carefully examined and lexical items that did not relate to the job descriptions and requirements for an ideal candidate were expelled. The key words under investigation are presented in Table II.
TABLE II. KEY WORDS IN THE COMPARED SUB-CORPORA

\begin{tabular}{|c|c|c|c|}
\hline \multicolumn{2}{|c|}{$\begin{array}{l}\text { Corpus of Texts for Leading } \\
\text { Positions (CLP) }\end{array}$} & \multicolumn{2}{|c|}{$\begin{array}{l}\text { Corpus of Texts for Non- } \\
\text { Leading Positions (CNLP) }\end{array}$} \\
\hline Key word & $K$ & Key word & $K$ \\
\hline leadership & 127.399 & diary & 132.239 \\
\hline Lead & 120.676 & experienced & 109.667 \\
\hline Strategic & 115.490 & duties & 100.523 \\
\hline Strategy & 105.292 & support & 79.598 \\
\hline Develop & 53.149 & busy & 74.664 \\
\hline Leader & 50.300 & organizing & 65.438 \\
\hline Growth & 46.803 & organized & 64.797 \\
\hline development & 45.764 & detail & 59.559 \\
\hline Vision & 43.302 & assisting & 58.185 \\
\hline New & 43.224 & creative & 55.607 \\
\hline developing & 39.457 & team & 52.095 \\
\hline Change & 39.346 & tasks & 42.402 \\
\hline Shape & 31.951 & attention & 42.173 \\
\hline strategies & 31.906 & PowerPoint & 40.994 \\
\hline objectives & 29.930 & advanced & 40.267 \\
\hline drive & 28.490 & friendly & 39.719 \\
\hline driving & 27.594 & enthusiastic & 36.068 \\
\hline bring & 26.801 & fantastic & 34.788 \\
\hline effective & 26.432 & arranging & 34.382 \\
\hline transformation & 26.432 & Microsoft & 33.547 \\
\hline success & 25.375 & Excel & 32.418 \\
\hline qualified & 25.046 & Word & 32.418 \\
\hline implementing & 20.976 & task & 30.415 \\
\hline insight & 20.332 & bright & 29.780 \\
\hline leading & 19.988 & liaising & 29.780 \\
\hline expertise & 19.986 & confident & 29.643 \\
\hline implement & 18.287 & preparing & 28.809 \\
\hline analytics & 15.975 & manner & 28.523 \\
\hline improvement & 15.626 & fast & 27.175 \\
\hline solution & 14.523 & diaries & 26.448 \\
\hline targets & 14.523 & great & 26.190 \\
\hline build & 13.621 & presentations & 25.528 \\
\hline improvements & 13.071 & skills & 23.188 \\
\hline integration & 13.071 & assist & 21.870 \\
\hline transform & 13.071 & initiative & 21.672 \\
\hline achieve & 12.709 & supportive & 21.356 \\
\hline ambitious & 12.415 & proactive & 20.959 \\
\hline analytical & 11.699 & keep & 20.450 \\
\hline goals & 11.618 & arrangements & 19.244 \\
\hline transformational & 11.618 & handle & 18.229 \\
\hline ambition & 10.920 & accurate & 17.191 \\
\hline influencing & 10.630 & amazing & 17.085 \\
\hline increase & 10.166 & liaise & 16.209 \\
\hline maximise & 10.166 & attitude & 15.600 \\
\hline challenges & 9.532 & communication & 15.077 \\
\hline strong & 9.262 & personable & 14.821 \\
\hline planning & 9.248 & processing & 14.821 \\
\hline intelligence & 9.143 & pressure & 14.580 \\
\hline transforming & 8.714 & juggle & 14.546 \\
\hline implementation & 8.589 & outgoing & 14.546 \\
\hline difference & 8.510 & assistance & 13.807 \\
\hline innovation & 7.517 & coordination & 13.807 \\
\hline innovative & 7.444 & liaison & 13.807 \\
\hline influence & 7.405 & preparation & 13.807 \\
\hline inspired & 7.262 & know & 13.704 \\
\hline optimise & 7.262 & perfect & 13.224 \\
\hline perspective & 7.262 & calm & 12.618 \\
\hline & & impressive & 12.618 \\
\hline & & coordinating & 12.577 \\
\hline & & good & 12.567 \\
\hline & & excellent & 12.306 \\
\hline & & fabulous & 11.902 \\
\hline & & sociable & 11.902 \\
\hline
\end{tabular}


TABLE II (continuation)

\begin{tabular}{|l|l|l|l|}
\hline & & flexible & 11.296 \\
\hline & vibrant & 10.630 \\
\hline & lively & 10.579 \\
\hline & hospitality & 10.425 \\
\hline & prioritise & 10.425 \\
\hline & responding & 10.425 \\
\hline & providing & 9.467 \\
\hline & handling & 9.361 \\
\hline & organise & 9.361 \\
\hline & arrange & 9.257 \\
\hline & humour & 9.257 \\
\hline & literacy & 9.257 \\
\hline & & efficient & 8.750 \\
\hline & & accurately & 7.934 \\
\hline & & polite & 7.934 \\
\hline & & reliable & 7.934 \\
\hline & & impeccable & 7.934 \\
\hline & & dynamic & 7.857 \\
\hline & & &
\end{tabular}

The highest keyness value (LL: log-likelihood value) does not show significant variation across the corpora: in the CNLP, it reaches around 132.239 for the lexeme diary, with the highest value of the lexeme leadership in the CLP being 127.399. As the keyword function in the corpus manager does not allow counting all the forms of one lexeme as lemma, the list includes all the grammar forms of one lexeme as different key words. So, the lemma diary, which is used in the plural form diaries, could have had a much higher keyness. This holds true for such lexemes as strategy (strategies), develop (developing), drive (driving), implement (implementing), lead (leading), transform (transforming), improvement (improvements), assist (assisting), liaise (liaising), etc.

The following sections will give account on the use of keywords in the two corpora: keywords employed in job descriptions that denote general actions, keywords representing skills and attributes required for an ideal candidate. Thus, the authors will be able to provide further details with respect to differences in the lexical choices and emerging patterns of meaning in the job advertisements under scrutiny.

\section{A. Keywords used in job descriptions}

For the purposes of this study, keywords denoting general actions have been considered as all those words that do not refer to skills or personal qualities required for an ideal candidate, but those that are used to describe duties or responsibilities. In this category, verbs or verbal forms are generally found whereas nouns are usually part of verbal collocation. Table III shows the keywords used to describe duties and responsibilities of ideal candidates as they are represented in the two corpora with absolute frequencies indicated in brackets. The table is divided into two parts that include the verbal keywords and nominal keywords.

The semantic analysis of the lexemes employed for the strategy of an ideal candidate representation in job advertisements for non-leading positions revealed the prevalence of lexis that belongs to the semantic categories of help, relationship, reciprocity. The semantic category of help includes lemmas of the verbs support, assist and
TABLE III. VERBAL AND NOMINAL KEYWORDS IN THE COMPARED SUBCORPORA WITH ABSOLUTE FREQUENCIES

\begin{tabular}{|c|c|}
\hline CPL & CNLP \\
\hline $\begin{array}{l}\text { lead (99), leading (98), develop } \\
(80) \text {, transform (9), } \\
\text { transforming (6), optimise (5), } \\
\text { maximize (7), achieve (20), } \\
\text { build (37), implementing (17), } \\
\text { drive 936), driving (19), shape } \\
(22)\end{array}$ & $\begin{array}{l}\text { support (42), organizing (56), } \\
\text { assisting (44), arranging (26), liaising } \\
(28) \text {, preparing (31), greeting (21), } \\
\text { respond (36), assist (36), supporting } \\
(71) \text {, handle (22), liaise (17), juggle } \\
\text { (11), coordinating (22), prepare (9), } \\
\text { prioritise (15), responding (15), } \\
\text { handling (14), organize (14), arrange } \\
(7)\end{array}$ \\
\hline 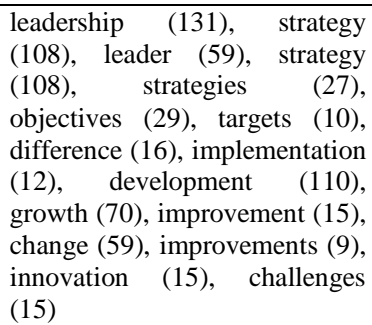 & $\begin{array}{l}\text { diary (100), diaries (20), assistance } \\
(15) \text {, coordination (15), liaison (15), } \\
\text { preparation (15), support (156) }\end{array}$ \\
\hline
\end{tabular}

corresponding nouns assistance, support. The semantic group of relationship is restricted to the subcategory of organizing and formed by lemmas of the verbs arrange, organize, coordinate, prepare, handle, prioritise and the nouns diary (diaries), coordination and preparation. The semantic category of reciprocity is represented by the lemma of the verbs liaise, respond and the noun liaison.

The semantic analysis of the lexemes employed for the strategy of a job description in advertisements for leading positions revealed the prevalence of lexis that belongs to the main three semantic categories of modification and change, power, and planning. The semantic category of modification and change includes lemmas of the verbs develop, change, improve, implement, transform and corresponding nouns improvement(s), development, transformation, change, etc.; the semantic group of power is represented by lemma of the verb lead, the nouns leader, leadership. The idea of planning is associated with the key words strategy, objective, target, etc.

Semantic analysis of the key lexemes reveals that in texts of job advertisements for leading positions, the lexis is employed that is aimed at construing an image of the leader that can provide a better future for the company that arises as a result of the ideal candidate activities and actions. As for the texts for non-leading positions, the lexis employed describes present time activities, and actions that describe the job are concentrated on the current needs of the company.

\section{B. Key words related to abilities and attributes of a suitable candidate}

The category of Appraisal Theory that is most relevant for the analysis of attributes, traits and abilities of suitable candidates is that of Judgment that associates either with social esteem or with social sanction. The traits of a suitable candidate can be categorised into two large groups: cognitive and non-cognitive skills. While cognitive skills include generic skills such as experience, knowledge, learning abilities etc., and special skills (i.e. ability to use Microsoft, Excel, Word etc.), the category that is mainly found in the sub-corpus 
for non-leading positions, non-cognitive skills embraces personal features and attributes that are used in the texts of the two corpora.

Cognitive skills are associated with the semantic category of Capacity that is represented by the lexemes experience, experienced, expertise, analytical skills, bright, etc. Noncognitive skills are related to the semantic category of Tenacity that is represented by the lexemes initiative, enthusiastic, tenacious, proactive, both of which are oriented towards social esteem. The category of Judgement that is oriented to social sanction is realized by the semantic subcategory of Propriety. This is marked by the nouns and collocations attention to detail, (highly) organised, keep an eye on, efficient, friendly, polite, strong inter-personal skills, excellent communicative skills, calm, discretion, (sense of) humour. The most common lexical items of the three domains, with the number of their absolute occurrences in the corpus, are included in Table IV.

The Capacity Category. The depiction of attributes and traits that are characteristic of a suitable candidate in the CLP is conveyed through the repeated use of the nouns, one collocation and an adjective. In the CNLP, the dominant noun skills forms various collocations and the prevailing adjective is experienced. The idea of intelligence is emphasized in both corpora; however, job advertisements for senior jobs are more focused on cognitive abilities of a suitable candidate as they are characterized by lexical density.

The Category of Tenacity. The second group of attitudinal lexis that belongs to the Category of Tenacity is mainly found in the CNLP whereas the CLP keyword list includes only two lexemes, ambition and ambitious, that convey the idea of intrinsic motivation a suitable candidate is expected to have. The lexical variety of lexemes related to this semantic domain is higher in the CNLP as the texts put strong emphasis on

TABLE IV. DISTRIBUTION OF LEXICAL ITEMS ACCORDING TO THE CATEGORIES OF APPRAISAL IN THE COMPARED SUB-CORPORA WITH INDICATED ABSOLUTE FREQUENCIES

\begin{tabular}{|c|c|}
\hline \multirow[t]{2}{*}{ CPL } & CNLP \\
\hline & Judgement: social esteem \\
\hline \multicolumn{2}{|r|}{ Capacity } \\
\hline 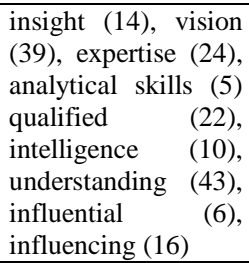 & $\begin{array}{l}\text { experienced (168), bright (28), skills (223), IT } \\
\text { skills (13), writing skills (4), organizational skills } \\
(17) \text {, management skills (17) }\end{array}$ \\
\hline \multicolumn{2}{|r|}{ Tenacity } \\
\hline $\begin{array}{l}\text { ambitious } \\
\text { ambition (14) }\end{array}$ & $\begin{array}{l}\text { proactive (44 dynamic (38), ), enthusiastic (33), } \\
\text { initiative (28), flexible (25), reliable (6), } \\
\text { impeccable (6) }\end{array}$ \\
\hline \multicolumn{2}{|r|}{ Judgement: social sanction } \\
\hline & $\begin{array}{l}\text { Propriety: organized (49), attention (42), detail- } \\
\text { oriented (4), keep an eye on (19), efficient (18) } \\
\text { friendly (40), communication skills (51), } \\
\text { hospitality (15), interpersonal skills (8), calm } \\
\text { (14), discretion (9), humour (7) }\end{array}$ \\
\hline
\end{tabular}

those candidates who are highly motivated to perform the current duties well.

The Category of Propriety. The third domain of the attitudinal lexis deals with social sanction, therefore, entailing the depiction of a suitable candidate as conforming to socially accepted norms and rules of behaviour. The analysis shows that job advertisements for senior positions do not use lexis that is related to these semantic categories whereas texts for junior jobs rely heavily on compliance of an ideal candidate with socially approved norms of behavior as the texts highlight sense of humour, politeness and discretion among other qualities. Besides, the focus is placed on communication skills that are favoured in most texts of the CNLP corpora while they are conspicuously absent in the texts for leading positions in the company.

\section{CONCLUSION}

This study provides quantitative data on keyword variation between job advertisements for leading and non-leading positions available on websites of the two national British papers, The Times and The Guardian. Substantial differences are observed in discursive practices used to describe jobs, skills and abilities required for an ideal candidate. Application of corpus linguistics methods enabled us to perform the key words analysis of lexis and provide answers to the research questions. The study reveals more evidence on socio-cultural differences in portraying an ideal candidate for senior and junior vacancies, and the authors hope that it addresses the gap and advances in the field of study.

The analysis of the lexical differences between the two corpora has revealed significant variation in discursive practices between the job advertisements for leading and nonleading vacancies.

The results of the keyword examination point to the fact that job descriptions for leading positions make use of lexis that is semantically different from those that describe nonleading positions. In the corpus of job advertisements that includes vacancies for executives, the semantic analysis of the lexemes, employed for the strategy of a suitable employee representation, revealed the prevalence of lexis with the semantic component of power, change, and planning. However, the corpus of job advertisements for junior jobs provides evidence that lexemes, employed in job descriptions, belong to the semantic category of help, organization and reciprocity. The first group of lexis construes a suitable candidate as a person who is result-oriented and is expected to bring about change to the company. The second group of lexis places a focus on day-to-day activities and implies that a suitable candidate is a person who conforms to rules and norms of the organization.

In addition to the differences described above, the analysis of lexis, denoting attributes and dispositions of a suitable candidate in relation to the categories of jobs under investigation, shows that key words in the CNLP point to the use of evaluation. At the same time, keyword data from the CLP corpus do not provide much evidence in this respect, being restricted to the sub-category of Capacity within a broader Category of Judgement that is common for discursive 
practices in this text type. As the data obtained show, the lexical items that belong to the evaluative category of Capacity are the most frequent in the two corpora indicating that companies prefer to lay emphasis on cognitive skills.

The analysis of keyword data in the two corpora revealed that the Category of Judgement, which is central to the type of texts under investigation, is represented by more subcategories in the CNLP corpus. The subcategory of Tenacity is mainly characteristic of junior jobs and is represented by varied vocabulary used to construe the portrayal of a suitable employee as having intrinsic motivation to work for his/her employer and determined to put every effort into the job to achieve maximum results. This holds true for lexis that is associated with social sanction and is used to depict a suitable employee as conforming to socially accepted norms and rules of behavior with the stress on communication skills that are found in most texts of the CNLP corpus.

The limitations of the study are that the amount of data, obtained through the identification of keywords, must be reduced so that it could be subject to manual analysis, but which may yield distorted or incomplete results. Another drawback is that variation of lexemes should be discussed in more detail to get a more nuanced picture of meaning patterns in the discursive practice. As some of the items convey very vague and abstract meanings, which makes it difficult for the potential applicant to interpret the requirements, they need to be further studied by delving more deeply into their meaning and context so that a more reliable impression of the patterns of meaning can be gained.

\section{Acknowledgment}

The research for this study was funded by the Russian Foundation for Fundamental Studies (RFFI), under grant 1504-00134 "Historical Discourse Studies: Issues, Methodology and Prospects".

\section{References}

[1] N. Fairclough, Discourse and Social Change. Cambridge: Polity Press, 1992.

[2] R. Wodak, "What CDA is about: a summary of its history, important concepts and its developments," in Methods of Critical Discourse Analysis, R. Wodak and M. Meyer, Eds, 2nd ed. London: Sage, 2009, pp. 1-13.

[3] R. Wodak and M. Meyer, (eds) Methods of Critical Discourse Analysis. 2nd ed. London: Sage, 2009.

[4] J.P. Gee, How to do Discourse Analysis: A Toolkit. New York: Routledge, 2011.

[5] J.R. Martin and P.R.R. White, The Language of Evaluation: Appraisal in English. Basingstoke: Palgrave Macmillan, 2005.

[6] V. Bhatia, Analysing Genre: Language Use in Professional Settings. Harlow: Longman, 1993.

[7] V. Bhatia, Worlds of Written Discourse. London: Continuum, 2004.

[8] J.M. Swales, Genre Analysis. English in Academic and Research Settings. Cambridge: Cambridge University Press, 1990.

[9] R.E. Ployhart, J.A. Weekley, and K. Baughman, "The structure and function of human capital emergence: a multilevel examination of the attraction-selection-attrition model," Academy of Management Journal, vol. 49(4), pp. 661-677, 2006.

[10] A. Furnham, "The content of job advertisements," The Talented Manager: 67 Gems of Business Wisdom. Palgrave Macmillan, pp. 7072, 2012.
[11] A. Rafaeli and A.L. Oliver, "Employment ads: a configurational research agenda," in Journal of Management Inquiry, vol. 7(4), pp. 342$358,1998$.

[12] P. Gillaerts, "From job announcement to recruitment advertising: the evolution of recruitment ads in a Flemish newspaper (1946-2010)," Genre Change in the Contemporary World: Short-term Diachronic Perspectives, G. Garzone, P. Catenaccio, and C. Degano, Eds. Lang (Bern)nr, 2012, pp. 263-276.

[13] A. Kuokkanen, P. Varje, and A. Vaananen, "Transformation of the Finish employee ideal in job advertisements from 1944 to 2009," Acta sociologica (United Kingdom), vol. 56(3), pp. 213-226, 2013.

[14] L.A. Kochetova and O.I. Volodchenkova, "A corpus study of dynamics of communicative and informative characteristics of announcements on employment in British linguistic culture," in Nauchni Dialog, vol. 7(55), pp. 45-55, 2016.

[15] N. Walters. A. Fage-Batler, "Danish job advertisements: increasing in complexity," Communication and Language at Work, 3, 2014, pp. 3852.

[16] B. Kheovichai, "Marketized university discourse: a synchronic and diachronic comparison of the discursive constructions of employer organizations in academic and business job advertisements," Discourse and Communication, vol. 8(4), pp. 371-390, 2014.

[17] L. M. Kureková, L.Mytna, M. Beblavý, C. Haita, and A. Thum-Thysen, "Employers' skill preferences across europe: between cognitive and non-cognitive skills," Journal of Education and Work, vol. 3, pp. 662$687,2015$.

[18] D.L. Paulhus, B.G. Westlake, S.S. Calvez, and P.D. Harms, "Selfpresentation style in job interviews: the role of personality and culture," Journal of Applied Social Psychology, vol. 43(10), pp. 2042-2059, 2013.

[19] K. Ahsan, M. Ho, and S. Khan, "Recruiting project managers: a comparative analysis of competencies and recruitment signals from job advertisements," Project management journal, vol. 44(5), pp. 36-54, 2013.

[20] J. Lacka-Badura, "Academic job postings as part of academic discourse: a cross-cultural perspective," Occupying Niches: Interculturality, Crossculturality and Aculturality in Academic Research, A. Lyda and K. Warshal, Eds., Second Language Learning and Teaching. Springer International Publishing Switzerland, 2014, pp. 217-234.

[21] L. Hodel, M. Formanowicz, S. Sczesny, J. Valdrova, and L. von Stockhausen, "Gender-Fair language job advertisements: a crosslinguistic and cross-cultural analysis," Journal of Cross-Cultural Psychology, Pre-published February 8, 2017.

[22] D. Rear, "Converging work skills? Job advertisements and generic skills in Japanese and Anglo-Saxon contexts," Asian Business and Management, vol. 12, pp. 173-196, 2013.

[23] de Cooman and R. Pepermans, "Potraying fitting values in job advertisements," Personnel Review, vol. 41(2), pp. 216-232, 2012.

[24] M.L. Gold and M.G. Grotti, "Do job advertisements reflect ACRL's standards for proficiencies for instruction librarians and coordinators?: a content analysis," The Journal of Academic Librarianship, vol. 39(6), pp. 558-565, 2013.

[25] P. Haan, Postmodifying Clauses in the English Noun Phrase. A Corpusbased Study. Amsterdam: Rodopi, 1989.

[26] M. Stubbs, Text and Corpus Analysis: Computer-assisted Studies of Language and Culture. Oxford, UK \& Cambridge, USA: Blackwell Publishers, 1996.

[27] P. Baker, Using Corpora in Discourse Analysis. London \& New York: Continuum, 2006.

[28] P. Baker, Using Corpora in Discourse Analysis. London: Continuum, 2008.

[29] A. Partington, "Modern diachronic corpus-assisted discourse studies on UK newspapers: an overview of the project," in Corpora, vol. 5, iss. 2, pp. 83-108, 2010.

[30] P. Baker and T. McEnery, (eds) Corpora and Discourse Studies: Integrating Discourse and Corpora. Hampshire: Palgrave Macmillan, 2015.

[31] R.J. Walker and W.J. Richard, "Patterns and meanings in discourse: theory and practice in corpus-assisted discourse studies 
(CADS)”. 麗澤大学紀要= in Reitaku University Journal, 98, pp. 129130, 2015.

[32] J. de Kock, "Gramática y corpus: los pronombres demostrativos," Revista de Filología Románica, vol. 14(1), pp. 291-298, 1997.

[33] J. de Kock, "Divergencias y convergencias en dos corpus de registros de lengua diferentes," Verba: Anuario Galego de Filoloxía, vol. 28, pp. 31$58,2001$.

[34] G. Thompson and S. Hunston, "Evaluation: an introduction," in Evaluation in Text: Authorial Stance and the Construction of Discourse. S. Hunston and G. Thompson, Eds. Oxford: Oxford University Press, 2000, pp. 1-27.

[35] M. Scot, "PC analysis of key words - and key key words," System, 25(2), pp. 233-245, 1997.

[36] M. Stubbs, "Three concepts of keywords," in Keyness in Texts. M. Bondi and M. Scott, Eds. Amsterdam: John Benjamins, 2010, pp. 2142.

[37] L. Anthony, AntConc (Version 3.4.3) [Computer Software]. Tokyo, Japan: Waseda University, 2014. Available from http://www.laurenceanthony.net/

[38] M. Jackson, "How far merit selection? Social stratification and the labour market," British Journal of Sociology, vol. 58(3), pp. 367-390, 2007. 